\title{
EDUCAÇÃO AMBIENTAL NO CONTEXTO ESCOLAR: CONSCIENTIZAÇÃO DE ESTUDANTES DA EDUCAÇÃO DE JOVENS E ADULTOS (EJA) NO ENSINO FUNDAMENTAL
}

\section{Environmental education in school context: awareness of youth and Adult Education Students (AES) in school education}

\author{
Amanda Costa Amorim- Universidade Estadual do Piauí \\ Carlos Jardel Araújo Soares - Instituto Federal de Educação, Ciências e Tecnologia do \\ Maranhão - IFMA
}

\begin{abstract}
RESUMO: O trabalho apresenta um estudo feito sobre a educação ambiental em uma escola com Educação de Jovens e Adultos (EJA) da cidade de Caxias - MA, propondo que a Educação Ambiental (EA) seja tratada no ambiente escolar, centrada nos princípios de colaboração, independência e interação entre os educandos. O objetivo foi identificar o nível de conscientização dos alunos da modalidade EJA sobre educação ambiental. Para a sua realização, foi feita pesquisa descritiva e bibliográfica, e aplicado um questionário para 60 alunos. Os principais resultados encontrados foram pouco conhecimento sobre o meio ambiente, reconheceram que a cidade tem problemas ambientais, no qual o principal agente causador é o homem. E o problema mais relevante foi a poluição dos rios. $\mathrm{O}$ veículo de comunicação mais utilizado para adquirir informação é a televisão, sendo perceptível a falta da busca pela leitura de livros, revistas e jornais a respeito do meio ambiente. Outra informação relevante foi que menos de $20 \%$ recebem conhecimento sobre Educação Ambiental por meio dos professores. Notou-se que os alunos dessa modalidade de ensino socializam seus conhecimentos no ambiente familiar e na comunidade, levando com que a informação repassada, atingisse de forma indireta, outras pessoas ligadas à escola de aplicação. Os alunos compreenderam a importância de contribuir com a preservação do meio ambiente, não só na escola, mas em casa com a família, responsabilizando-se em preservar o meio em que vive.
\end{abstract}

Palavras-chave: Conscientização. Educação. Meio Ambiente. Sensibilização.

ABSTRACT: The present work aims to present a study about environmental education in a school with Youth and Adult Education (EJA) in the city of Caxias - MA. The present work proposes that Environmental Education (EE) be treated in the school environment, centered on the principles of cooperation, autonomy and interaction among learners. It aimed to identify the level of awareness of the students of the EJA modality on environmental education. For its accomplishment was made descriptive research and bibliographical research. The study with 60 students and the questionnaires applied in class. The main results of this research were that students have little knowledge about the environment. The most commonly used vehicle for acquiring information is television. It is clear that students are looking for little reading of books, magazines and newspapers about the environment. Another relevant information was that less than $20 \%$ received knowledge about Environmental Education through teachers. It was noticed that the students of this modality of education socialize their knowledge in the familiar environment and in the community, causing that the information passed on indirectly affects other people connected to the school of application. The students understood the

Educação, Psicologia e Interfaces, Volume 3, Número 2, p. 34-56, Maio/Agosto, 2019.

ISSN: 2594-5343. DOI: https://doi.org/10.37444/issn-2594-5343.v3i2.142 
Educação ambiental no contexto escolar: conscientização de estudantes da Educação de Jovens e Adultos (EJA) no ensino fundamental

importance of contributing to the preservation of the environment, not only at school but at home with the family, taking responsibility for preserving the environment in which they live.

Keywords: Awareness. Education. Environment. Sensitization.

\section{INTRODUÇÃO}

O mundo vive uma época de grandes transformações sociais, econômicas, políticas e ambientais, que nem sempre são positivas. Junto aos progressos técnicocientíficos, convive-se com a degradação da vida humana e dos valores sociais e individuais. $\mathrm{O}$ assunto acerca do ecossistema tornou-se de extrema importância na sociedade, devido aos inúmeros desastres ambientais por interferência, muitas vezes, das ações humanas. Por tanto, a responsabilidade de gerenciar e preservar os recursos representados diversas espécies vivas, assim como sua ambiência, são exclusivas do homem, beneficiando suas descendências, patrimônio que, hoje, encontra-se em risco por uma combinação de fatores adversos.

A Educação de Jovens e Adultos é uma modalidade de ensino que prima pelo sujeito, formando uma das políticas nacionais que favorecem para inclusão social, trazendo de volta à escola, jovens e adultos que por diversas dificuldades não permaneceram no ensino regular (RUMMERT, 2007).

A primeira tentativa da aplicação do EJA como um direito, teve início a partir da década de 1930, destacando-se as campanhas de alfabetização que aconteceram nas décadas de 1940 e 1950. Porém somente a partir da Lei de Diretrizes e Bases (LDB) (Lei $n^{\circ}$ 9.394) de 1996 que definiu a EJA como aquela educação destinada àqueles que não tiveram acesso ou continuidade de estudos no ensino fundamental e médio na idade regular, assegurando a gratuidade aos jovens e aos adultos (BRASIL, 1996; FREIRE; CARNEIRO, 2016).

A Educação Ambiental (EA) é um processo de aprendizagem permanente baseado no respeito a todas as formas de vida, ou seja, uma estratégia que busca a conservação do meio, trazendo o bem-estar global da vida humana através da conservação da qualidade e da diversidade do ecossistema.

Educação, Psicologia e Interfaces, Volume 3, Número 2, p. 34-56, Maio/Agosto, 2019.

ISSN: 2594-5343. DOI: https://doi.org/10.37444/issn-2594-5343.v3i2.142 
No entanto, para adotar uma postura educacional baseadas nos valores anteriormente citados, é válida a realização de uma reavaliação da Educação Ambiental no séc. XX, considerando a definição de Educação Ambiental do séc. XXI. Não sendo interpretado como erros, mas com a finalidade de adaptar o conceito de Educação Ambiental no século atual, a partir de uma profunda reflexão sobre as posturas que, até então, eram aceitas (PADIAL, 2013).

Essa educação segue uma nova filosofia de vida, uma nova cultura comportamental que busca um compromisso da humanidade com o presente e o futuro do ecossistema. Ou seja, todos têm direito de um meio ambiente equilibrado, cabendo ao Poder Público e a sociedade a preservação e conservação do ecossistema, atribuindo ao primeiro a promoção da educação ambiental em todos os níveis de escolaridade e a conscientização da sociedade quanto a conservação (BRASIL, 1988), que o Ministério da Educação e Cultura através da Portaria $n^{\circ}$ 678/91, estabeleceu a incorporação da Educação Ambiental no currículo escolar dos diferentes níveis e modalidades de ensino (BRASIL, 1991).

Por meio do presente trabalho, buscou-se estudar a percepção e práticas dos estudantes da modalidade de ensino de Educação de Jovens e Adultos (EJA) a respeito do meio ambiente. Para isso perguntamos: Qual o nível de sensibilização e conscientização dos alunos de uma Escola de Educação de Jovens e Adultos (EJA) da cidade de Caxias - MA?

\section{EDUCAÇÃO AMBIENTAL E CAPACITAÇÃO DE PROFESSORES}

Segundo Pedrini (2002), historicamente, as primeiras sociedades humanas buscavam acumular riquezas para o próprio sustento e, muitas delas, disseminavam-se geograficamente à procura de recursos naturais. Uma vez vista como fonte de vida, a natureza agora passava a ser fonte de lucro, assim o homem praticamente extinguiu alguns dos recursos que poderiam ser renováveis, com finalidade de obter poder.

Para Guimarães (1997 apud PEDRINI, 2002), a Educação Ambiental tem sido abordada em concomitância às práticas pelos próprios educadores, no entanto, ainda circula sem objetivo e métodos de ação por seus praticantes. Dias (1993), afirma que a Educação Ambiental se dá através de simples aulas ministradas pela equipe de educação

Educação, Psicologia e Interfaces, Volume 3, Número 2, p. 34-56, Maio/Agosto, 2019. 
Educação ambiental no contexto escolar: conscientização de estudantes da Educação de Jovens e Adultos (EJA) no ensino fundamental

de uma instituição de ensino. Já no campo empresarial há um discurso confuso por incoerência de reais propósitos.

Segundo Mellows (1972 apud DIAS, 2004), “a Educação Ambiental é um processo de desenvolvimento progressivo com o meio ambiente, em um completo e sensível entendimento das relações do homem com o ambiente". Na Conferência de Tbilisi foi estabelecido que a Educação Ambiental deve ser um processo educativo para a resolução dos reais problemas do ecossistema, que acontece por participação individual e coletiva, através de uma participação ativa.

Dias (2004) cita que a Educação Ambiental deve se fazer parte de todas as fases da vida, dando início em casa, permitindo o desenvolvimento de uma mentalidade em que haja respeito do homem para com a natureza, definindo o ecossistema como o meio formado pelos aspectos bióticos, abióticos e a cultura do ser humano (sua tecnologia, construções, artes, ciências, religiões, valores estéticos e morais, ética, política, econômica, etc.).

A educação pública brasileira passa por modificações. A exigência constitucional de que todos tenham a garantia de cursar o ensino fundamental e ter acesso ao ensino médio não é o bastante para propiciar qualidade no ensino escolar. Manter o aluno na escola e combater a repetência ainda são problemas a serem superados, apesar da grande discussão sobre as formas adequadas para a organização do tempo escolar e da adoção de metodologias capazes de reverter esse quadro.

Desse modo, qualquer novidade pedagógica que venha a ser inserida no contexto escolar passa pelo professor. Os professores são alvo de críticas quando há problemas nas escolas, mas raramente lhes pedem soluções. No entanto, suas opiniões e ações são de extrema importância. Afinal, são eles que decidem o que acontece em suas salas de aula (SANDHOLTZ, 1997, p.173).

Piaget (1985, p. 129) afirmou que "As mais perfeitas reformas ficam sem conclusão se não há professores disponíveis, em qualidade e número suficientes”, e ao verificar que novas metodologias "não atingirão jamais a escola se os professores não os incorporarem até traduzi-los em realizações originais". Nesse aspecto, torna-se necessário oferecer uma formação continuada ao professor, que auxilie o seu aperfeiçoamento profissional, a fim de garantir o sucesso pretendido.

Educação, Psicologia e Interfaces, Volume 3, Número 2, p. 34-56, Maio/Agosto, 2019.

ISSN: 2594-5343. DOI: https://doi.org/10.37444/issn-2594-5343.v3i2.142 
O professor passa por momentos de incerteza frente à tarefa de ensinar. Conseguir atuar de forma ativa, levando o educando a desenvolver um olhar crítico da realidade e integrar as dimensões da problemática ambiental de forma mais profunda, requer a preparação do educador. Torna-se necessário então fornecer condições de apoio na busca por novas metodologias e tecnologias para atuação em sala de aula visando corrigir eventuais defasagens ou complementando o seu aprendizado através de cursos de capacitação e aperfeiçoamento de docentes.

Repensar a formação inicial de professores é urgente, pois o que se tem, na prática, não tem sido suficiente. É necessário considerar que o professor precisa estar preparado para acompanhar esta sociedade de aceleradas mudanças, de enormes demandas educacionais no que tange ao processo ensino aprendizagem e das tecnologias inovadoras. Nesse contexto, é necessária uma formação capaz de preparar o professor para uma atuação engajada, não só com a aprendizagem dos alunos, mas também com os aspectos que envolvem a formação cidadã interligada ao direito de aprender, à capacidade de entender o mundo e compreender seus direitos e deveres, tendo o conhecimento como um processo de construção e não como algo pronto e acabado que será aprendido e posteriormente transmitido (LOPES et al. 2017).

Esse processo formativo deve ser coerente com a mediação, como forma de regulação, que o professor é realmente capaz de empreender em sua prática, propiciando a articulação entre as atividades de desenvolvimento pessoal e profissional. É também necessário que exista uma preocupação em relacionar o trabalho de aquisição dos conhecimentos com o de construção das competências docentes básicas e que têm relação direta com essa prática. Só assim a docência será capaz de superar uma rotina da tradição pedagógica que reduz o ensino à reprodução copiada e ao treinamento mecanizado (GASQUE; TESCAROLO, 2010).

Carvalho e Gasque (2018) argumentam que o professor precisa questionar o papel e as metodologias de ensino-aprendizagem para uma educação transformadora. Para tanto, há necessidade de um ensino voltado para a reflexão, uma vez que, quanto maior a capacidade de refletir, mais significativo e mais aprofundado será o processo de pensar empregado na elaboração do conhecimento. A capacidade de reflexão do aluno é elemento crucial para o discernimento do conhecimento, dada sua possibilidade de tornar o aluno capaz de interpretar, comparar, ponderar e integrar as informações. 
Educação ambiental no contexto escolar: conscientização de estudantes da Educação de Jovens e Adultos (EJA) no ensino fundamental

A capacitação docente formal é imprescindível para currículos inovadores. O planejamento e a execução de atividades educativas devem ser preocupação nuclear para o grupo de professores que pretenda implantar novas metodologias de ensinoaprendizagem. Além das ações educativas sistematizadas, atividades alternativas podem contribuir para o aperfeiçoamento da função docente. Ao lado dos objetivos centrais propostos para estas atividades, agregam-se objetivos que favorecem também a capacitação dos professores. São procedimentos auxiliares informais, não sistemáticos, que podem contribuir para a formação docente durante um processo de mudança (ALMEIDA; FERREIRA FILHO, 2008).

Além disso, Pereira, Fusinato e Gianotto (2017) reforçam a importância de o professor entender que a docência é um processo dinâmico, vivencial e muito mais complexo do que um simples treinamento para a docência, e que a maior parte da sua experiência vem da sua vivência em sala de aula. A sala de aula é um ambiente dinâmico e mutável, tornando o processo de ensino-aprendizagem altamente complexo e impondo aos professores a necessidade de conhecer e saber utilizar várias metodologias e recursos de ensino que possibilitem atingir a maior quantidade possível de alunos na sala de aula. Quanto mais variado e rico for o meio intelectual, metodológico ou didático fornecido pelo professor, maiores condições ele terá de desenvolver uma aprendizagem significativa de seus alunos.

E, para atender às demandas do modelo de educação centrado no aluno e na compreensão dos processos envolvidos na busca e no uso da informação, Carvalho e Gasque (2018) defendem a necessidade da inclusão de conteúdos curriculares na formação básica do professor que o capacitem a lidar eficaz e eficientemente com a informação. Uma possibilidade seria a inserção de um conjunto de disciplinas que permitisse a reflexão sobre o seu papel na construção da sociedade da aprendizagem, e que também o instruísse no desenvolvimento da própria competência informacional.

\section{DESENVOLVIMENTO SUSTENTÁVEL}

O conceito de desenvolvimento sustentável surgiu com o nome de ecodesenvolvimento nos anos 1970 (ROMEIRO, 2012), foi fruto de um processo de discussão que inspirou doutrinas, teorias e políticas desde que a revolução industrial

Educação, Psicologia e Interfaces, Volume 3, Número 2, p. 34-56, Maio/Agosto, 2019.

ISSN: 2594-5343. DOI: https://doi.org/10.37444/issn-2594-5343.v3i2.142 
embasou as preocupações sistemáticas com o desenvolvimento. Essa revolução acelerou o crescimento econômico, diversificou as atividades produtivas e criou sociedades mais complexas e dotadas de problemas sociais e ambientais novos. A disseminação desigual das atividades industriais e a subordinação de atividades extrativas, agrícolas e pecuárias aos imperativos da produção industrial criaram distinções e desigualdades não apenas entre o conjunto de nações e regiões, mas dentro das próprias nações e regiões mais industrializadas (BURSZTYN; DRUMMOND, 2009).

Em 1983, a Secretaria-Geral da Organização das Nações Unidas (ONU) convidou a médica e ex-ministra da Noruega Gro Haalen Brundtland para estabelecer e presidir a Comissão Mundial para o Meio Ambiente e o Desenvolvimento (CMMAD), também conhecida como Comissão de Brundtland. Em 1987, foi publicado o Relatório Brundtland, conhecido como "Nosso Futuro Comum", que colocou o conceito de Desenvolvimento Sustentável na agenda política, o qual é definido como aquele capaz de "satisfazer as necessidades das gerações presentes, levando em consideração as necessidades das gerações futuras". Nesse relatório, o conceito de Desenvolvimento Sustentável representa uma tentativa de impulsionar o desenvolvimento de tecnologias limpas, e individualizar as responsabilidades sociais sobre os danos ambientais, assegurando os processos econômicos e industriais (FREITAS; MARQUES, 2017).

A crescente preocupação global com as atuais ameaças à biodiversidade levou à criação da Convenção sobre Diversidade Biológica (CDB), um fórum internacional para discutir os meios mais eficazes pelos quais países com biodiversidade significativa poderiam participar efetivamente de ações de conservação. Este fórum foi criado durante a Conferência das Nações Unidas sobre Meio Ambiente e Desenvolvimento (popularmente conhecida como a "Cúpula da Terra", "Rio-92" ou "Eco-92"), realizada no Brasil em 1992 (FILARDI et al. 2018).

A Cúpula da Terra adotou a Agenda 21, um amplo projeto de ação para alcançar desenvolvimento sustentável em todo o mundo. Nesta agenda, os governos delinearam um programa detalhado para afastar o mundo do atual modelo insustentável de crescimento econômico, direcionando para atividades que protejam e renovem os recursos ambientais. As áreas de ação incluem: proteger a atmosfera; combater o desmatamento, a perda de solo e a desertificação; prevenir a poluição da água e do ar;

Educação, Psicologia e Interfaces, Volume 3, Número 2, p. 34-56, Maio/Agosto, 2019. 
Educação ambiental no contexto escolar: conscientização de estudantes da Educação de Jovens e Adultos (EJA) no ensino fundamental

deter a destruição das populações de peixes e promover uma gestão segura dos resíduos tóxicos (ONU, 2019).

Na concepção de Abramovay (2010), desenvolvimento sustentável é o processo de ampliação permanente das liberdades dos indivíduos em condições que estimulem a manutenção e a regeneração dos serviços prestados pelos ecossistemas às sociedades humanas. Ele é formado por uma diversidade de fatores determinantes, mas cujo seguimento depende, justamente, da presença de um pilar estratégico entre seus protagonistas decisivos. Nesse sentido, a maior preocupação é o conteúdo da própria cooperação humana e a maneira como, no âmbito dessa cooperação, as sociedades optam por usar os ecossistemas de que dependem.

Segundo Romeiro (2012), para ser sustentável, o desenvolvimento deve ser economicamente eficiente, socialmente desejável e ecologicamente equilibrado. Dias (2004) reforça essa concepção afirmando que é impossível haver desenvolvimento sustentável se a destruição ambiental ainda for uma realidade, pois estes recursos atendem a necessidade de todos os seres vivos, caso o manejo seja eficiente. No entanto, o homem priorizou o crescimento econômico sem se importar com as consequências, tornando o desenvolvimento insustentável, levando ao esgotamento dos recursos naturais dos quais a humanidade necessita.

De acordo com o Ministério do Meio Ambiente, o desenvolvimento sustentável sugere qualidade em vez de quantidade, utilizando a política dos 5 R's (reduzir, reutilizar ou reaproveitar, reciclar, repensar e recusar). A política vem para contribuir como instrumento eficaz para a solução dos problemas do lixo, priorizando a redução do consumo e o reaproveitamento dos materiais em relação à sua própria reciclagem. Os 5 R's fazem parte de um processo educativo com o objetivo de mudar os hábitos no cotidiano dos cidadãos. Trata-se, portanto, de uma alternativa para levar o cidadão a repensar seus valores e práticas, reduzindo o consumo exagerado e o desperdício (BRASIL, 2019).

Gasque e Tescarolo (2010) destacam que o desenvolvimento sustentável integral é uma das respostas potencialmente mais eficazes para a situação presente do mundo e se concretiza na superação das contradições sociais, mediante a expansão das liberdades substantivas e reais de cada ser humano. Isso implica a criação de novas formas de 
solidariedade internacional, ancorada por um pensar e um agir abrangentes e duradouros, sempre focando na sustentabilidade global, que adota como princípios organizadores o respeito à vida, à dignidade humana e a preservação do meio ambiente por intermédio do uso intensivo do conhecimento.

\section{MATERIAL E MÉTODO}

Neste estudo, utilizou-se a pesquisa bibliográfica e descritiva. Os dados primários foram obtidos através da pesquisa de campo. Segundo Marconi e Lakatos (2006), considera-se a pesquisa um procedimento formal, com método de pensamento reflexivo que requer um tratamento científico, estabelecendo o caminho para conhecer a verdade absoluta ou em sua parcialidade. De acordo ainda com os autores, toda pesquisa requer levantamento de dados de variadas fontes, quaisquer que sejam os métodos ou técnicas usadas, sendo coletadas através de documentação direta ou indireta.

A pesquisa foi realizada na escola pública municipal Antenor Gomes Viana Junior, com alunos da modalidade de Educação de Jovens e Adultos (EJA) do turno noturno. A escola fica situada na Avenida Santos Dumont, bairro Antenor Viana, no município de Caxias, estado do Maranhão, e atende um total de 640 alunos, dos anos iniciais $\left(1^{\circ}\right.$ ao $5^{\circ}$ ano $)$ e anos finais $\left(6^{\circ}\right.$ ao $9^{\circ}$ ano) do ensino fundamental, bem como 04 turmas na modalidade EJA, divididas em $1^{\mathrm{a}}, 2^{\mathrm{a}}, 3^{\mathrm{a}}$ e $4^{\mathrm{a}}$ etapa, totalizando 21 turmas. A escolha desta escola deve-se ao número e à diversidade de alunos atendidos, pois os mesmos são provenientes tanto da sede quanto das comunidades rurais, também está localizada num local estratégico próximo ao deposito de lixo e por conter famílias carentes de informação que provavelmente desmatam o meio ambiente.

Os dados foram coletados por meio de aplicação de um questionário distribuídos para 100 alunos contendo 10 (dez) questões objetivas em uma amostra de conveniência no qual 60 alunos se voluntariaram a participar da pesquisa, essa quantidade foi ao acaso de acordo com os alunos que se propuseram a responder no momento. Com o objetivo de avaliar qual o nível de conscientização destes em relação à Educação Ambiental, tendo em vista que tais alunos são pais e chefes de família que atuam nessa comunidade na qual estão inseridos, e que têm pouco acesso às informações relatadas na mídia por trabalharem durante todo o dia.

\section{RESULTADOS E DISCUSSÃO}

Educação, Psicologia e Interfaces, Volume 3, Número 2, p. 34-56, Maio/Agosto, 2019.

ISSN: 2594-5343. DOI: https://doi.org/10.37444/issn-2594-5343.v3i2.142 
Educação ambiental no contexto escolar: conscientização de estudantes da Educação de Jovens e Adultos (EJA) no ensino fundamental

Foi distribuído um total de 100 questionários, dos quais 60 foram respondidos e 18 foram devolvidos; destes, 13 foram excluídos por conterem respostas duplicadas ou ausentes nos itens referentes aos dados sociodemográficos, e outros 09 foram descartados por não terem completado os itens referentes ao conhecimento sobre Educação Ambiental (taxa de respostas válidas: 60\%).

Os dados do perfil sociodemográfico dos alunos incluídos na pesquisa estão apresentados na tabela 1 abaixo, onde percebeu-se que, do total de 60 alunos, $62 \%$ eram do sexo feminino, $85 \%$ tinham mais de 20 anos de idade, $70 \%$ eram solteiros, e $80 \%$ trabalhavam durante todo o dia.

Tabela 1. Perfil sociodemográfico dos alunos participantes da pesquisa, Caxias - MA, 2018.

\begin{tabular}{|c|c|c|c|}
\hline & Variáveis & $\mathbf{N}$ & $\%$ \\
\hline & \multicolumn{3}{|l|}{ Sexo } \\
\hline & Masculino & 23 & 38,0 \\
\hline & Feminino & 37 & 62,0 \\
\hline & \multicolumn{3}{|l|}{ Faixa etária } \\
\hline & $\leq 20$ anos & 09 & 15,0 \\
\hline & $>20$ anos & 51 & 85,0 \\
\hline & \multicolumn{3}{|l|}{ Estado civil } \\
\hline & Solteiro (a) & 42 & 70,0 \\
\hline & Casado (a)/União estável & 18 & 30,0 \\
\hline \multicolumn{4}{|c|}{ Trabalha durante todo 0} \\
\hline & Sim & 48 & 80,0 \\
\hline & Não & 12 & 20,0 \\
\hline & Total & 60 & 100,0 \\
\hline
\end{tabular}

Fonte: Pesquisa direta, 2018.

O perfil dos alunos desta pesquisa mostra a realidade do público que frequenta o EJA, geralmente pessoas estigmatizadas pela sociedade e com poucas oportunidades de acesso ao ensino regular. A maioria da amostra composta por mulheres evidencia uma característica ainda bastante presente na atualidade brasileira, onde o papel histórico da mulher na sociedade é relegado às tarefas domésticas, à responsabilidade pela educação e alimentação dos filhos, bem como pelos cuidados à família de maneira geral. Tais responsabilidades fazem com que a mulher abdique de sua formação educacional em

Educação, Psicologia e Interfaces, Volume 3, Número 2, p. 34-56, Maio/Agosto, 2019.

ISSN: 2594-5343. DOI: https://doi.org/10.37444/issn-2594-5343.v3i2.142 
detrimento do bem-estar da família. Nesse aspecto, a EJA é uma possibilidade de concluir os estudos sem que estes interfiram no seu papel de cuidadora do lar.

Este resultado é reforçado pela faixa etária e estado civil dos alunos pesquisados, majoritariamente com idade acima de 20 anos e casados, reiterando a dificuldade destas pessoas em concluírem a educação básica no tempo limite, e de conciliarem suas obrigações familiares com o anseio de estudar. $\mathrm{O}$ fato de a maioria dos entrevistados também trabalharem durante todo o dia também corrobora a busca pela modalidade EJA, visto que estes indivíduos têm que trabalhar para garantir o sustento família, além da indisponibilidade da oferta de ensino regular no turno noturno.

No que tange ao entendimento do conceito de meio ambiente, quando questionados sobre este tema, 50\% responderam era Amazônia. Alguns compreendiam que meio ambiente era a existência diversas espécies de animais, vegetais e microrganismos em determinado hábitat natural (30\%), conforme o gráfico 1.

Gráfico 1. O que você compreende por meio ambiente?

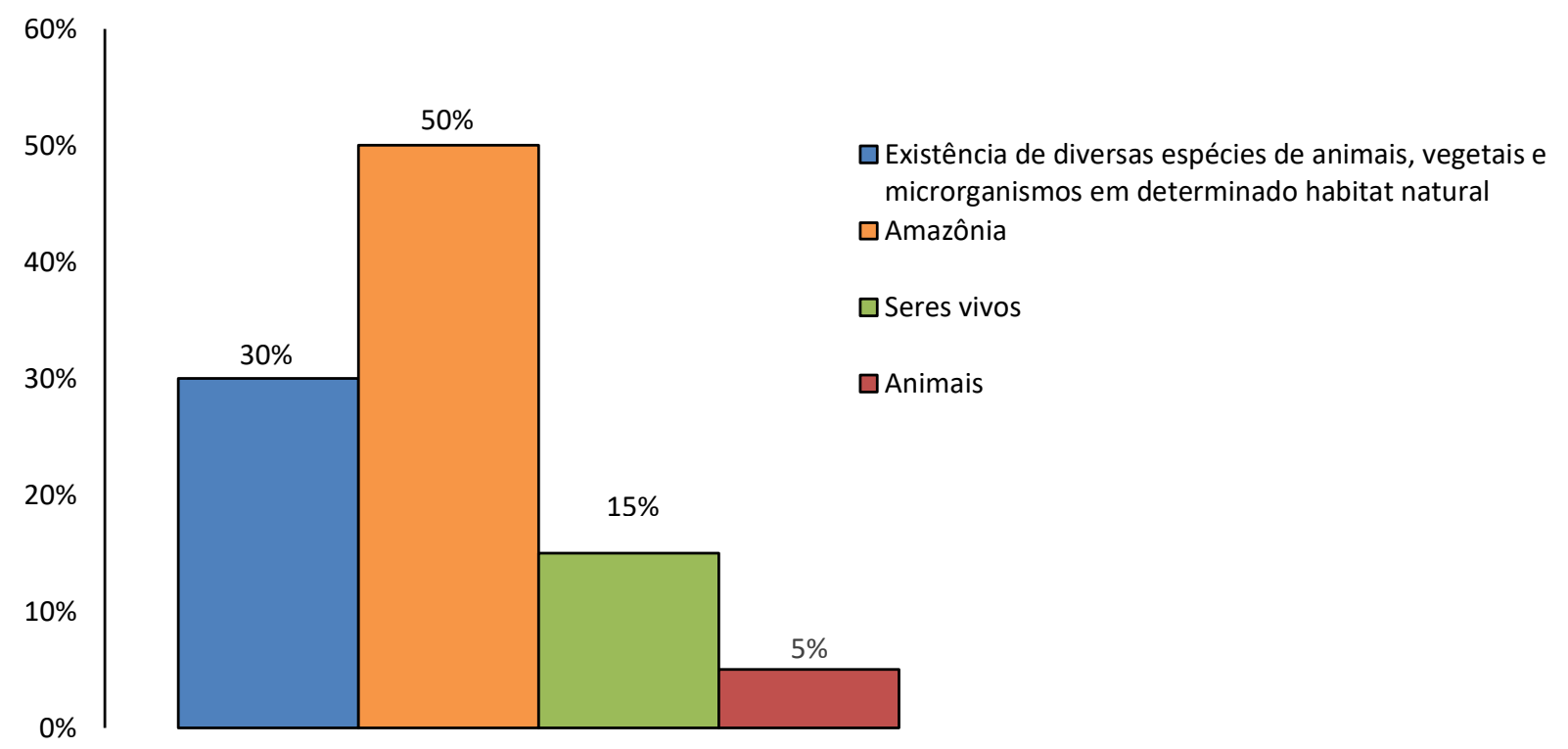

Fonte: Pesquisa direta, 2018.

Em pesquisa pelo termo meio ambiente é possível encontrar diferentes definições que certamente serão correspondentes com as diversas áreas do saber (Ecologia, Filosofia, Geografia, etc.), refletindo distintas finalidades e concepções. Tendo em foco a EA, concorda-se com a definição de Reigota (2014, p. 36):

Educação, Psicologia e Interfaces, Volume 3, Número 2, p. 34-56, Maio/Agosto, 2019. 
Educação ambiental no contexto escolar: conscientização de estudantes da Educação de Jovens e Adultos (EJA) no ensino fundamental

Defino meio ambiente como: um lugar determinado e/ou percebido onde estão em relação dinâmica e em constante interação os aspectos naturais e sociais. Essas relações acarretam processos de criação cultural e tecnológica e processos históricos e políticos de transformações da natureza e da sociedade.

Observou-se que conhecimento sobre meio ambiente foi fragmentado entre a maioria dos alunos dessa modalidade de ensino, mas se fez presente em uma pequena parte, ainda que numa pequena porcentagem. Dessa forma, os resultados apontam um certo distanciamento entre as perspectivas de meio ambiente dos estudantes e o proposto nas Diretrizes Curriculares Nacionais para Educação Ambiental (DCNEA) (BRASIL, 2012). Mesmo que a temática socioambiental venha sendo discutida amplamente, e esteja presente nas DCNEA, essas perspectivas podem não ter alcançado ainda as escolas em todas as suas modalidades de ensino.

Observa-se assim a importância das DCNEA, que são voltadas às instituições de ensino, onde citam o desenvolvimento da visão integrada de Meio Ambiente e a necessidade de superação da visão naturalista presente nas práticas pedagógicas das instituições. Acredita-se que as DCNEA podem colaborar para uma reflexão sobre as práticas de EA presentes nas instituições escolares.

Dada a inter-relação da sociedade com o meio ambiente, a magnitude dos problemas ambientais e a importância do desenvolvimento sustentável, é necessário conhecer a definição do ambiente, pois muitas pessoas ainda não conhecem o significado e a dimensão filosófica e política deste meio. Portanto, é importante que o homem tenha um conhecimento preciso sobre o ambiente em que ele vive. Isso depende, em grande parte, de que as gerações presentes e futuras possam subsistir; para isso, é necessário, e contribui de maneira significativa, a implementação da Educação Ambiental que garanta que, em todas as atividades de cada cidadão, tenha sua proteção em mente, para que seja possível alcançar um desenvolvimento econômico e social sustentável (SANTIESTEBAN et al., 2011).

Quanto aos problemas ambientais no município de Caxias - MA, 94\% dos alunos afirmaram a existência desses, contra $6 \%$ que afirmavam o contrário, conforme o gráfico 2 abaixo. Dentre os problemas vivenciados no cotidiano dos alunos, o mais citado foi desmatamento (48\%), seguido de lixos urbanos (36\%).

Educação, Psicologia e Interfaces, Volume 3, Número 2, p. 34-56, Maio/Agosto, 2019.

ISSN: 2594-5343. DOI: https://doi.org/10.37444/issn-2594-5343.v3i2.142 
Gráfico 2. Existem problemas ambientais no município de Caxias - MA?

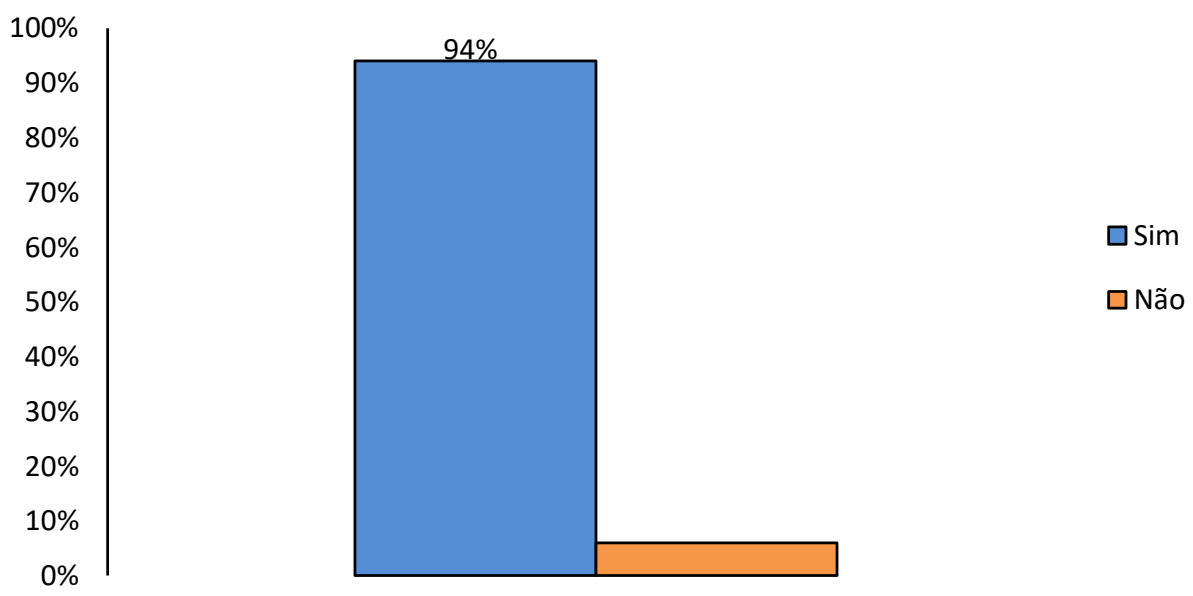

Fonte: Pesquisa direta, 2018.

Jiménez-Denis, Villalón-Legrá e Evora-Larios (2017) colocam que a mitigação dos danos causados por esses eventos pressupõe mudanças significativas no trabalho educativo realizado pela escola, fundamentalmente orientado a transformar a prática da relação existente entre os modos de ação que o aluno manifesta nos diferentes contextos em que atua e os identificou problemas ambientais. Nesse sentido, expressa-se que a educação ambiental para o desenvolvimento sustentável é uma alternativa viável para canalizar processos educativos nessa direção, reconhecendo a importância de um processo educativo que incorpore as dimensões econômica, político-social e ecológica do desenvolvimento sustentável de forma integrada e gradual à educação dos alunos e se expresse em formas de pensar, sentir e agir responsável perante o meio ambiente.

Em relação ao responsável pelo surgimento de problemas ambientais, a ação do homem foi apontada como a maior responsável (83\%) (Gráfico 3). Os alunos consultados informaram ainda que participam da preservação do meio ambiente, separando lixo úmido do seco ou não jogando lixo no chão. Os mesmos disseram que não se prestam a queimar matas.

O homem tem sido capaz de modificar o ambiente com suas atividades para atender as necessidades: a capacidade de controlar e usar o fogo mudou a vegetação natural, domesticação e de pastagem herbívoros levou a discussão sobre pastoreio e erosão do solo. O cultivo de plantas também causou a destruição da vegetação natural 
Educação ambiental no contexto escolar: conscientização de estudantes da Educação de Jovens e Adultos (EJA) no ensino fundamental

para o trabalho de cultivo das culturas e a demanda por lenha levou ao desnudamento das montanhas e ao esgotamento de florestas inteiras.

Gráfico 3. Quem é o maior responsável pelo surgimento de problemas ambientais?

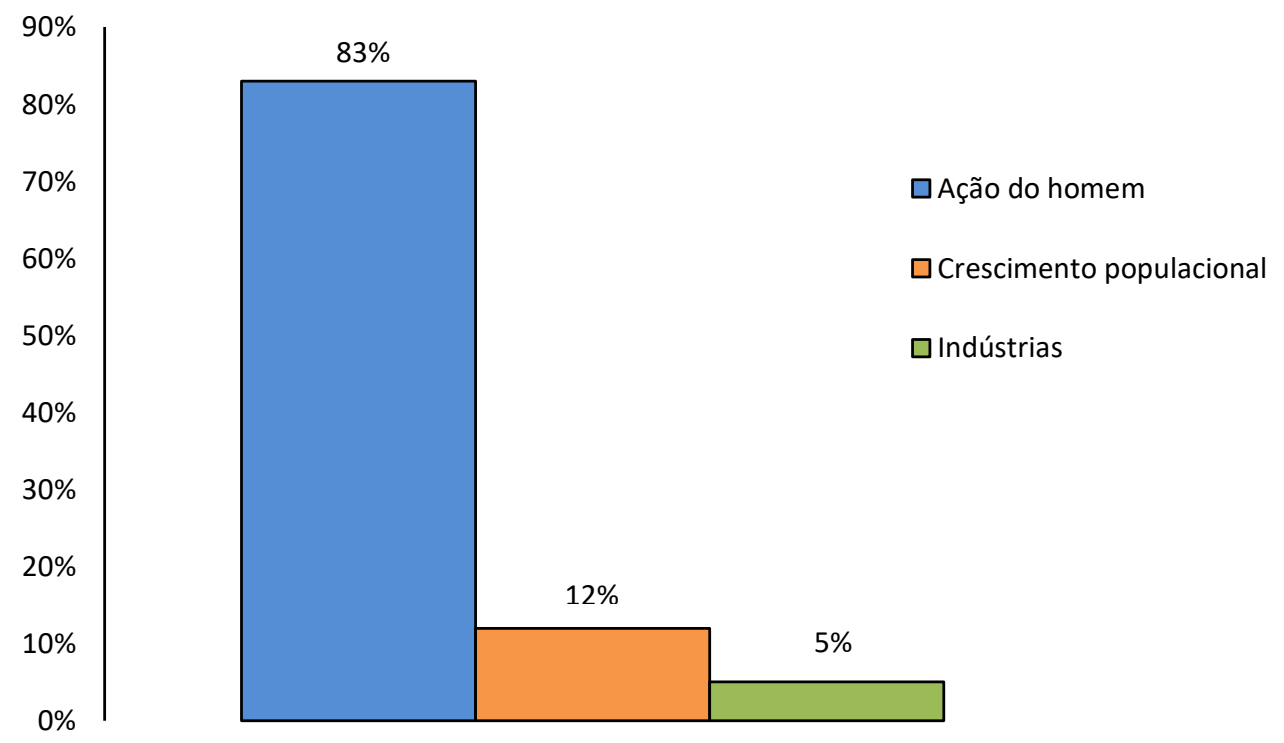

Fonte: Pesquisa direta, 2018.

O problema real veio com o boom das atividades industriais e a exploração massiva de combustíveis fósseis e outros recursos naturais, que marcaram boa parte do século 20, atingindo dimensões realmente irracionais. O homem poluiu rios e mares e cidades, lançou à atmosfera grandes volumes de gases que destroem a camada de ozônio, capazes de mudar o clima do planeta, reduziu sumidouros naturais ou pontos de absorção desses gases para desmatar vastas extensões de florestas, degradando solos e destruindo verdadeiros tesouros da diversidade biológica. Talvez, involuntariamente, a espécie humana se tornou a principal depredadora do meio ambiente de sua própria sobrevivência, ameaçada também nos dias de hoje por modelos econômicos que mergulharam milhões de pessoas na pobreza extrema (SANTIESTEBAN et al. 2011).

Quando questionados sobre os principais problemas ambientais existentes, os alunos apontaram a poluição dos rios (27\%), seguido de corte de árvores e queimadas (23\%) e lixo a céu aberto (20\%), conforme o gráfico 4 abaixo.

Gráfico 4. Quais os principais problemas ambientais existentes no mundo?

Educação, Psicologia e Interfaces, Volume 3, Número 2, p. 34-56, Maio/Agosto, 2019.

ISSN: 2594-5343. DOI: https://doi.org/10.37444/issn-2594-5343.v3i2.142 


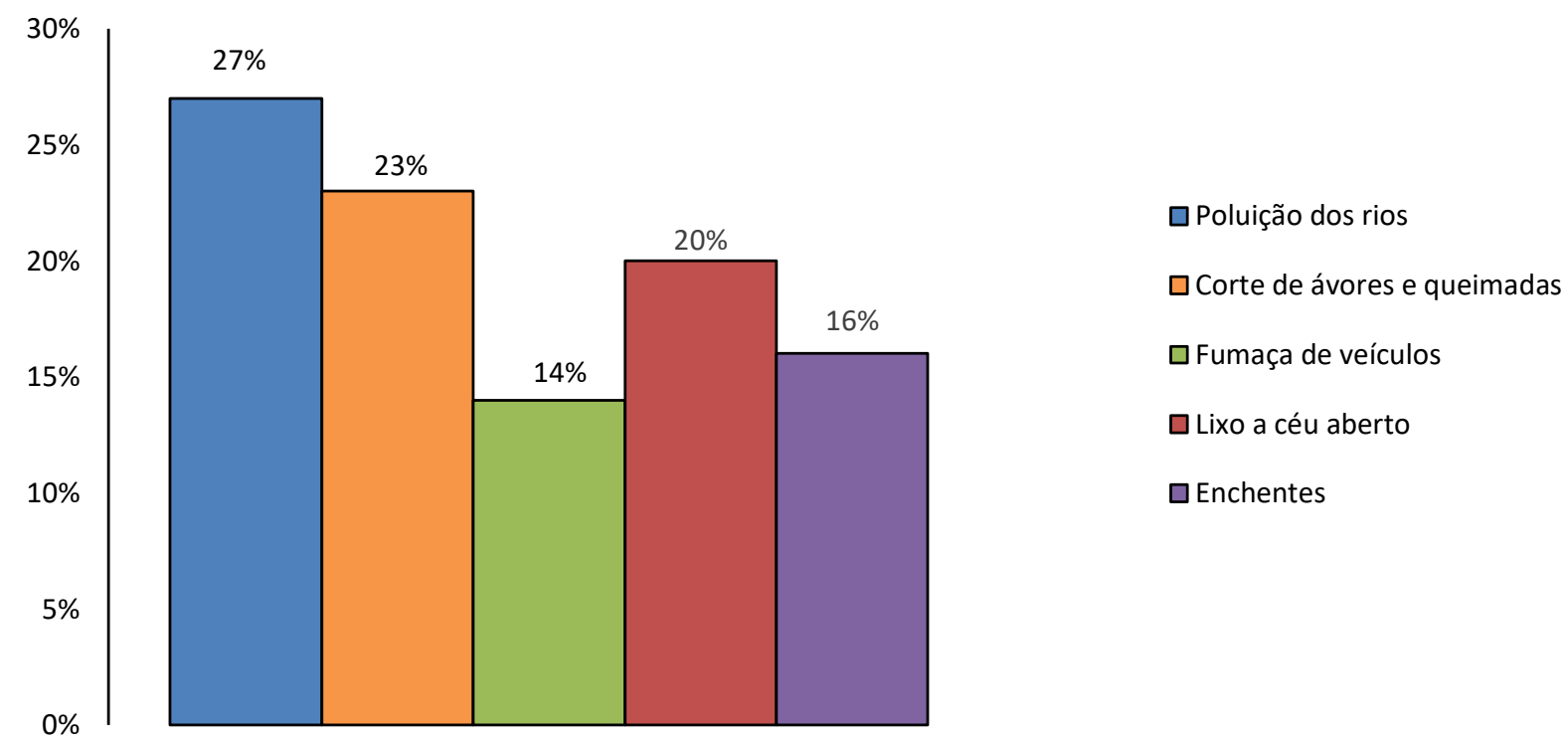

Fonte: Pesquisa direta, 2018.

Jiménez-Denis, Villalón-Legrá e Evora-Larios (2017) destacam que a existência desses problemas e sua exacerbação ao longo do tempo causaram mudanças significativas na magnitude, frequência e intensidade dos fenômenos naturais originados nas diversas regiões do planeta. Exemplos incluem terremotos, furacões, tempestades, inundações, deslizamentos de terra, secas, incêndios florestais, tsunamis, furacões, erupções vulcânicas, ondas de calor, entre outros; aqueles que anualmente causam enormes perdas de vidas humanas, destruição de infraestrutura econômica e social, bem como um impacto negativo sobre os ecossistemas.

Freitas e Marques (2017) salientam que as questões socioambientais constituemse de preocupações legítimas e de crescente interesse social, pois demandam compreensões das complexas relações que se estabelecem entre ciência, tecnologia, sociedade e ambiente. Reconhece-se que, ao se trabalhar as questões socioambientais, torna-se impossível esgotá-las no âmbito da sala de aula, tanto para fins de ensino como de pesquisa. Contudo, reconhece-se, também, que atualmente há a necessidade de se considerar a emergência dos contextos de (in)sustentabilidade.

Em relação às fontes de informações sobre Educação Ambiental, a maioria dos alunos (50\%) afirmou obter informações na televisão. Apenas 16\% afirmaram que costumam receber informações sobre meio ambiente dos professores, e somente 4\% disseram que leem livros ou revistas sobre o assunto, ou assistem notícias em programas de emissoras locais (4\%), como mostrado no gráfico 5 abaixo. 
Gráfico 5. De onde você obtém informações sobre Educação Ambiental?

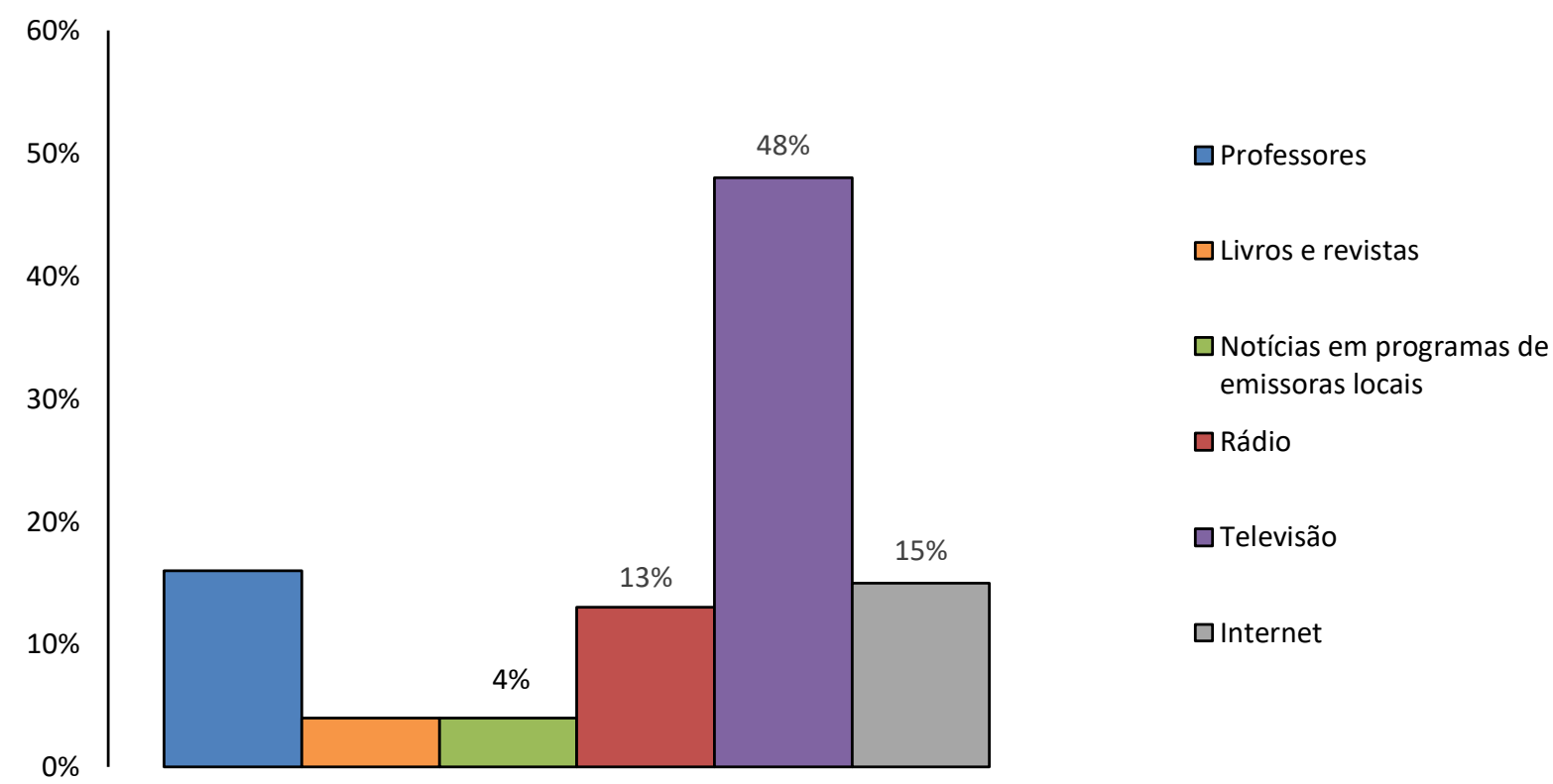

Fonte: Pesquisa direta, 2018.

O professor tem o papel de ser o mediador das questões ambientais, o que não quer dizer que ele deve saber tudo sobre o meio ambiente para desenvolver um trabalho de qualidade com seus alunos, mas que ele esteja preparado e engajado a ir à busca de conhecimentos e informações e transmitir aos alunos a noção de que o processo de construção de conhecimentos é constante. Para isso, o professor precisa buscar junto com os alunos mais informações, com o objetivo de desenvolver neles uma postura crítica diante da realidade ambiental e de construírem uma consciência global das questões relativas ao meio ambiente para que possam assumir posições relacionadas com os valores referentes à sua proteção e melhoria (MEDEIROS et al. 2011).

O contexto escolar, por meio do ensino, conhecimentos, habilidades e competências, torna-se transcendental para a identificação do patrimônio cultural e, portanto, para a compreensão e as ações no mundo. A educação ambiental deve integrar a abordagem homem-território e a relação homem-natureza-território, estabelecendo um diálogo de consciência do ambiente natural, o que torna necessário abordar recursos naturais de forma complementar, redes sociais, as redes de convivência, as redes de 
estabelecimento humano e a abordagem cultural, para que expliquem como a sociedade ocupa, transforma, constrói e ordena o espaço (QUINTANA-ARIAS, 2017).

Medeiros et al. (2011) destacam ainda que a educação ambiental nas escolas contribui para a formação de cidadãos conscientes, aptos para decidirem e atuarem na realidade socioambiental de um modo comprometido com a vida, com o bem-estar. Para isso, é importante que, mais do que informações e conceitos, a escola se disponha a trabalhar com atitudes, com formação de valores e com mais ações práticas do que teóricas para que o aluno possa aprender a amar, respeitar e praticar ações voltadas à conservação ambiental. A escola é o lugar onde o aluno irá dar continuidade ao seu processo de socialização, no entanto, comportamentos ambientalmente corretos devem ser aprendidos na prática, no decorrer da vida escolar com o intuito de contribuir para a formação de cidadãos responsáveis.

No último questionamento, a maioria dos alunos (42\%) apontam que a população em geral deve assumir a responsabilidade para resolver os problemas ambientais municipais e de maneira geral, englobando problemas recorrentes em todo o mundo, e $30 \%$ consideram que você individualmente deve contribuir para solução dos problemas ambientais, como mostra o gráfico 6.

Gráfico 6. Quem deveria assumir a responsabilidade para resolver problemas ambientais municipais e de maneira geral?

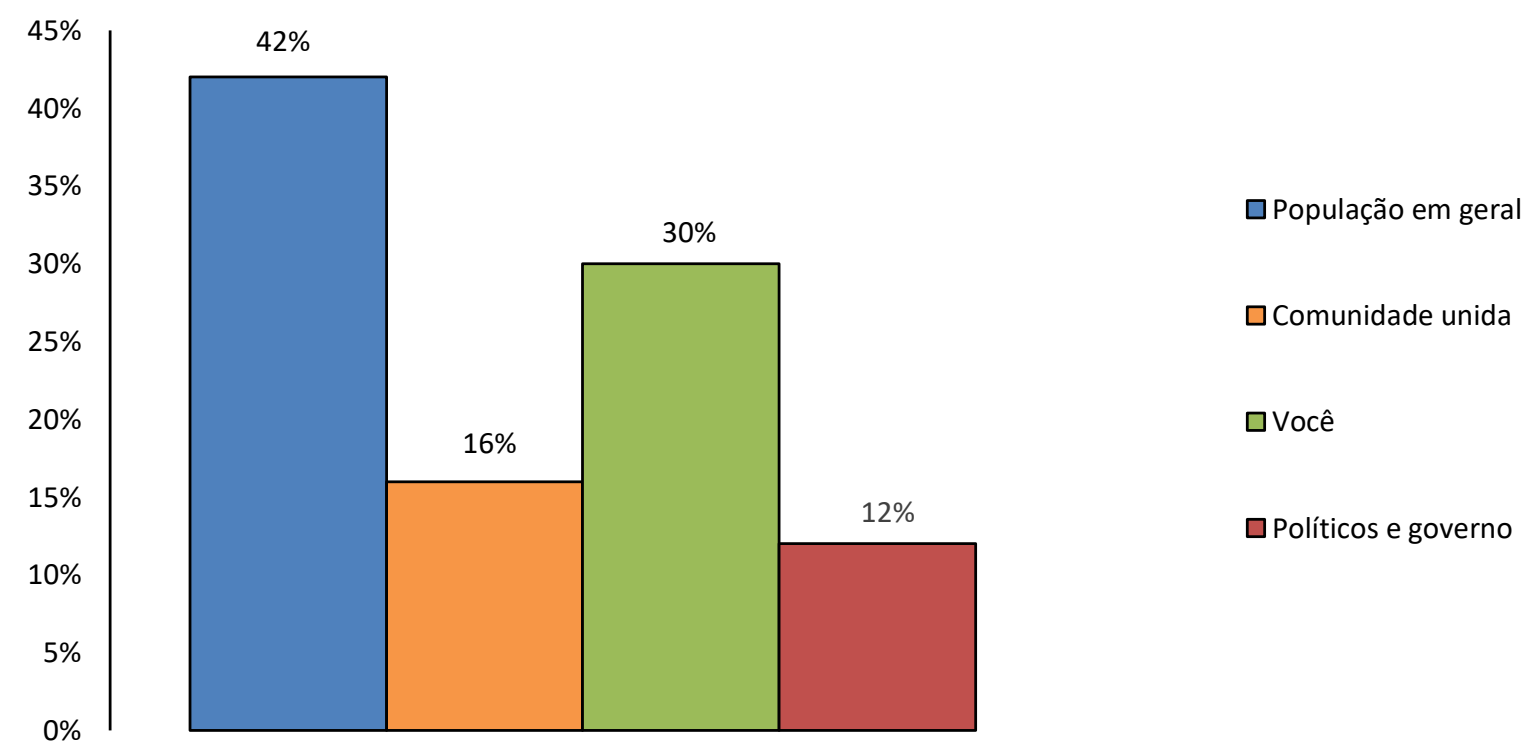

Fonte: Pesquisa direta, 2018.

Educação, Psicologia e Interfaces, Volume 3, Número 2, p. 34-56, Maio/Agosto, 2019. 
Na conservação e proteção de um ambiente propício à vida, Santiesteban et al. (2011) citam que cada pessoa tem uma importante responsabilidade para cumprir, uma ação positiva para executar e uma missão social para realizar, alcançar: que outros cidadãos sejam defensores dela. Portanto, é muito importante dizer que é necessário promover uma consciência universal para tornar o problema conhecido para homens e mulheres de todas as idades, incluindo crianças que habitam o planeta.

Ao final da pesquisa, onde se desenvolveu o conteúdo sobre a EA, fez-se necessário uma ação mais concreta para o processo de sensibilização e conscientização dos alunos, onde ministrou-se uma palestra sobre EA, com orientações como descartar os resíduos sólidos e realizar a coleta seletiva. Finalizando, apresentou-se em forma de vídeo a Carta Escrita de 2070, no intuito de instigar a reflexão dos alunos sobre o planeta que iremos deixar de herança para as gerações futuras.

Através deste trabalho, os alunos adquiriram uma visão mais ampla sobre a problemática ambiental, percebendo a importância de contribuir para a preservação do meio ambiente, não somente na escola, mas também em casa, sendo que a educação ambiental se tornou um exercício para a cidadania, tendo como objetivo a conscientização dos alunos do mundo em que vivem, mostrando que se pode ter qualidade de vida sem desrespeitar o meio ambiente, o projeto ensina a importância da natureza e de como utilizar os recursos naturais de forma responsável, mas para que ocorra uma mudança real da situação é indispensável à união do governo, da sociedade e da escola.

\section{CONSIDERAÇÕES FINAIS}

O estudo permitiu constatar que os alunos da modalidade EJA necessitam de mais conhecimento sobre o meio ambiente, evidenciado também pelo alto índice de desconhecimento do conceito de biodiversidade, que deverá ser ministrado pelos seus educadores. Com base nos dados obtidos nesta pesquisa, é possível afirmar que, entre os problemas ambientais vivenciados nos dias atuais, está o desmatamento e queimadas por consequência da ação do homem.

Ressalta-se que o foco na dimensão individual da EA conservadora não contribui para o engajamento cidadão dos estudantes com a questão ambiental. Os motivos para

Educação, Psicologia e Interfaces, Volume 3, Número 2, p. 34-56, Maio/Agosto, 2019.

ISSN: 2594-5343. DOI: https://doi.org/10.37444/issn-2594-5343.v3i2.142 
tais constatações não foram o objetivo dessa pesquisa, no entanto, a literatura destaca algumas causas como: a formação de professores, a estruturação do currículo, ensino descontextualizado, ineficiência de políticas públicas para efetivação da EA e problemas estruturais da Educação Básica.

O período de seca anual em diversas regiões deixa o ambiente mais propício a queimadas, inclusive na cidade de Caxias - MA, apontado como uma problemática, segundo respostas dos alunos. Outra situação recorrente é a poluição urbana, como o acondicionamento de lixo urbano de forma inadequada, muitas vezes em terrenos baldios ou áreas verdes, além da ocorrência de desmatamento, sendo todas estas ações prejudiciais para o meio ambiente, e causadas por ações humanas. Ainda, uma minoria dos alunos entrevistados apontou os jornais, livros e revistas sobre o meio ambiente como fonte primária de informação sobre o tema em questão.

Assim, nota-se por meio deste estudo a urgência da promoção da Educação Ambiental, em todos os níveis de ensino, em especial no EJA, favorecendo a difusão da questão sobre o cuidado com o meio ambiente e, ainda, o benefício de sua preservação para o desenvolvimento humano e a proteção de suas gerações.

Nesse sentido, acredita-que os resultados desta pesquisa possam contribuir para uma reflexão e melhor entendimento por parte da população em geral, professores e alunos, bem como das autoridades governamentais acerca da importância de preservar e cuidar do meio ambiente por meio do desenvolvimento sustentável no intuito de garantir uma melhor qualidade de vida e a subsistência das gerações vindouras.

Portanto, a Educação Ambiental constitui-se numa das ferramentas mais eficientes, capaz de favorecer a apreensão da realidade socioambiental, nas complexas relações sociedade-natureza; ao mesmo tempo que contribui para a compreensão fundamentada sobre os elementos que desenham a atual crise ambiental.

\section{REFERÊNCIAS}

ABRAMOVAY, R. Desenvolvimento sustentável: qual a estratégia para o Brasil? Novos estud. - CEBRAP, São Paulo, n. 87, p. 97-113, jul. 2010. Disponível em: <http://www.scielo.br/scielo.php?script=sci_arttext\&pid=S010133002010000200006\&lng=en\&nrm=iso>. Acesso em: 30 jan. 2019.

BRASIL. Ministério da Educação. Conselho Nacional de Educação. Conselho Pleno. Resolução no 2, de 15 de junho de 2012. Estabelece as Diretrizes Curriculares 
Educação ambiental no contexto escolar: conscientização de estudantes da Educação de Jovens e Adultos (EJA) no ensino fundamental

Nacionais para a Educação Ambiental. Brasília: Diário Oficial da União, 2012.

Disponível em:

$\leq$ http://portal.mec.gov.br/index.php?option=com_docman\&view=download\&alias $=109$ 88-rcp002-12-pdf\&category_slug=maio-2012-pdf\&Itemid=30192>. Acesso em: 28 abr. 2018.

BRASIL. Ministério da Educação. Gabinete do Ministro. Portaria nº 678, de 14 de maio de 1991. Brasília: Diário Oficial da União, 1991. Disponível em:

〈http://www.consultaesic.cgu.gov.br/busca/dados/Lists/Pedido/Attachments/522300/RE SPOSTA_PEDIDO_Portaria_678_-_Parte_1.pdf $>$. Acesso em: 14 mai. 2018.

BRASIL. Ministério da Educação. Secretaria de Educação Fundamental Parâmetros curriculares nacionais: terceiro e quarto ciclos: apresentação dos temas transversais. Brasília: Ministério da Educação, 1998.

BRASIL. Ministério do Meio Ambiente. A política dos 5 R's. Brasília: Ministério do Meio Ambiente, 2019. Disponível em:

〈http://www.mma.gov.br/component/k2/item/9410-a-pol\%C3\%ADtica-dos-5-rs.html>. Acesso em: 27 jan. 2019.

BRASIL. Presidência da República. Casa Civil. Subchefia de Assuntos Jurídicos. Constituição da República Federativa do Brasil de 1988. Brasília: Diário Oficial da União, 1988. Disponível em:

<http://www.planalto.gov.br/ccivil_03/constituicao/constituicao.htm>>. Acesso em: 20 mai. 2018.

BRASIL. Presidência da República. Casa Civil. Subchefia de Assuntos Jurídicos. Lei no 9.394, de 20 de dezembro de 1996. Estabelece as diretrizes e bases da educação nacional. Brasília: Diário Oficial da União, 1996. Disponível em: 〈http://www.planalto.gov.br/ccivil_03/Leis/L9394.htm>. Acesso em: 18 mai. 2019.

BURSZTYN, M.; DRUMMOND, J.A. Desenvolvimento sustentável: uma ideia com linhagem e legado. Sociedade e Estado, Brasília, v. 24, n. 1, p. 11-15, jan./abr. 2009. Disponível em:

〈https://www.researchgate.net/publication/277042153_Desenvolvimento_sustentavel_u ma_ideia_com_linhagem_e_legado>. Acesso em: 19 fev. 2019.

CARVALHO, L.F.; GASQUE, K.C.G.D. Formação continuada de professores e bibliotecários para o letramento informacional: a contribuição da educação a distância. Transinformação, Campinas, v. 30, n. 1, p. 107-119, abr. 2018. Disponível em: $\langle$ http://www.scielo.br/scielo.php?script=sci_arttext\&pid=S0103-

37862018000100107\&lng=en\&nrm=iso>. Acesso em: 27 fev. 2019.

DIAS, G.F. Educação ambiental: princípios e práticas. $3^{a}$ ed. São Paulo: Gaia, 1993.

CARVALHO, L.F.; GASQUE, K.C.G.D. Educação ambiental: princípios e práticas. $9^{a}$ ed. São Paulo: Gaia, 2004.

Educação, Psicologia e Interfaces, Volume 3, Número 2, p. 34-56, Maio/Agosto, 2019.

ISSN: 2594-5343. DOI: https://doi.org/10.37444/issn-2594-5343.v3i2.142 
FILARDI, F.L. et al. Brazilian Flora 2020: Innovation and collaboration to meet Target 1 of the Global Strategy for Plant Conservation (GSPC). Rodriguésia, Rio de Janeiro, v. 69, n. 4, p. 1513-1527, dez. 2018. Disponível em: <http://www.scielo.br/scielo.php?script=sci_arttext\&pid=S217578602018000401513\&lng=en\&nrm=iso>. Acesso em: 16 fev. 2019.

FREIRE, P.C.M.; CARNEIRO, M.E.F. Reflexões sobre a educação de jovens e adultos: contradições e possibilidades. Rev. Bras. Educ. Prof. Tecnol., v. 1, n. 10, p. 34-43. 2016. Disponível em: 〈http://www2.ifrn.edu.br/ojs/index.php/RBEPT/article/view/3469>. Acesso em: 18 mai. 2018.

FREITAS, N.M.S.; MARQUES, C.A. Abordagens sobre sustentabilidade no ensino CTS: educando para a consideração do amanhã. Educ. rev., Curitiba, n. 65, p. 219235, set. 2017. Disponível em:

$\leq$ http://www.scielo.br/scielo.php?script=sci_arttext\&pid=S010440602017000300219\&lng=en\&nrm=iso>. Acesso em: 30 jan. 2019.

GASQUE, K.C.G.D.; TESCAROLO, R. Desafios para implementar o letramento informacional na educação básica. Educ. rev., Belo Horizonte, v. 26, n. 1, p. 41-56, abr. 2010. Disponível em: $<\mathrm{http}: / / \mathrm{www}$.scielo.br/scielo.php?script=sci_arttext\&pid=S010246982010000100003\&lng=en\&nrm=iso>. Acesso em: 16 fev. 2019.

JIMÉNEZ-DENIS, O.; VILLALÓN-LEGRÁ, G.; EVORA-LARIOS, O.E. La educación para la percepción de riesgos de desastres como prioridad del trabajo educativo en la escuela cubana. Educare, Heredia, v. 21, n. 3, p. 385-396, dez. 2017. Disponível em: $\langle$ http://www.scielo.sa.cr/scielo.php?script=sci_arttext\&pid=S140942582017000300385\&lng=en\&nrm=iso>. Acesso em: 16 fev. 2019.

LOPES, R.A.S. et al. A história da formação de professores de ciências naturais dos últimos anos de educação primaria em Goiás. Rev. Fac. Cienc. Tecnol., Bogotá, n. 41, p. 109-127, jun. 2017. Disponível em:

$\leq$ http://www.scielo.org.co/scielo.php?script=sci_arttext\&pid=S012138142017000100109\&lng=en\&nrm=iso>. Acesso em: 29 jan. 2019.

MARCONI, M.A.; LAKATOS, E.M. Metodologia do Trabalho Científico. $6^{\text {a }}$ ed. São Paulo: Atrás, 2006.

MEDEIROS, A.B. et al. A importância da educação ambiental na escola nas séries iniciais. Rev. Faculdade Montes Belos, v. 4, n. 1, set. 2011. Disponível em: 〈http://www.terrabrasilis.org.br/ecotecadigital/pdf/a-importancia-da-educacaoambiental-na-escola-nas-series-iniciais.pdf>. Acesso em: 22 fev. 2019.

ORGANIZAÇÃO DAS NAÇÕES UNIDAS DO BRASIL. A ONU e o meio ambiente. Brasília: ONU, 2019. Disponível em: 〈https://nacoesunidas.org/acao/meio-ambiente/>. Acesso em: 21 fev. 2019.

PADIAL, K. Coleta Seletiva: conheça o lixo produzido pela escola e garanta o descarte correto. Rev. Gestão Escolar (Editora Abril), v. 5, n. 25, abr./mai. 2013. Disponível 
Educação ambiental no contexto escolar: conscientização de estudantes da Educação de Jovens e Adultos (EJA) no ensino fundamental

em: 〈https://gestaoescolar.org.br/conteudo/209/coleta-seletiva-na-escola $>$. Acesso em: 14 jun. 2018.

PEDRINI, A.G. Educação Ambiental: reflexões e práticas contemporâneas. $5^{\mathrm{a}}$ ed. Petrópolis: Vozes, 2002.

PEREIRA, R.F.; FUSINATO, P.A.; GIANOTTO, D.E.P. A prática pluralista na formação inicial de professores de Física. Ens. Pesqui. Educ. Ciênc., Belo Horizonte, v. 19, e2682. 2017. Disponível em: 〈http://www.scielo.br/scielo.php?script=sci_arttext\&pid=S198321172017000100220\&lng=en\&nrm=iso>. Acesso em: 18 fev. 2019.

PIAGET, J. Psicologia e pedagogia. Rio de Janeiro: Forense Universitária, 1985.

QUINTANA-ARIAS, R.F. La educación ambiental y su importancia en la relación sustentable: Hombre-Naturaleza- Territorio. Rev. Latinoam. Cienc. Soc. Niñez Juv, Manizales, v. 15, n. 2, p. 927-949, jul. 2017. Disponível em: 〈http://www.scielo.org.co/scielo.php?script=sci_arttext\&pid=S1692715X2017000200010\&lng=en\&nrm=iso >. Acesso em: 14 fev. 2019.

REIGOTA, M. O que é Educação Ambiental. 2a ed. São Paulo: Brasiliense, 2014.

ROMEIRO, A.R. Desenvolvimento sustentável: uma perspectiva econômico-ecológica. Estudos Avançados, v. 26, n. 74, p. 75-92. 2012. Disponível em:

<http://www.journals.usp.br/eav/article/view/10625/12367 > Acesso em: 18 fev. 2019.

RUMMERT, S.M. A educação de jovens e adultos trabalhadores brasileiros no século XXI. O "novo" que reitera antiga destituição de direitos. Rev. Ciênc. Educ., v. 2, p. 35 50, jan./abr. 2007. Disponível em:

〈http://forumeja.org.br/sites/forumeja.org.br/files/sisifo0203_rummert.pdf $>$ Acesso em: 14 jun. 2018.

SANDHOLTZ, J.H. et al. Ensinando com tecnologia: criando salas de aula centradas nos alunos. Porto Alegre: Artes Médicas, 1997.

SANTIESTEBAN, I.V. et al. Problemas ambientales y su tratamiento a través del sistema educacional cubano. Cuadernos de Educación y Desarrollo, v. 3, n. 29, p. 131, jul. 2011. Disponível em: 〈http://www.eumed.net/rev/ced/29/srmt.pdf $>$. Acesso em: 29 jan. 2019.

\section{Credenciais da/os autora/es}

AMORIM, Amanda Costa. Graduada em Licenciatura em Ciências Biológicas pela Universidade Estadual do Piauí. Pós-Graduanda em Educação e Ensino de Ciências

Educação, Psicologia e Interfaces, Volume 3, Número 2, p. 34-56, Maio/Agosto, 2019.

ISSN: 2594-5343. DOI: https://doi.org/10.37444/issn-2594-5343.v3i2.142 
pelo Instituto Federal de Educação, Ciências e Tecnologia do Maranhão - IFMA

Campus Caxias. E-mail: amannda.amorim@hotmail.com

SOARES, Carlos Jardel Araújo. Mestre em Biodiversidade, Ambiente e Saúde pela Universidade Estadual do Maranhão - UEMA. Especialista em Biologia Parasitária pelo Instituto Federal de Educação, Ciências e Tecnologia do Piauí - IFPI e em Gerenciamento de Recursos Ambientais pelo Centro Federal de Educação Tecnológica do Piauí - CEFET/PI. Graduado em Licenciatura Plena em Ciências Biológicas pela Universidade Estadual do Piauí - UFPI. Professor do Instituto de Educação, Ciências e Tecnologia do Maranhão - IFMA Campus Caxias.

Endereço para correspondência: Amanda Costa Amorim. E-mail:

amannda.amorim@hotmail.com

Como citar este artigo (Formato ABNT): AMORIM, Amanda Costa; SOARES, Carlos Jardel Araújo. Educação ambiental no contexto escolar: conscientização de estudantes da Educação de Jovens e Adultos (EJA) no ensino fundamental. Educação, Psicologia e Interfaces, v. 3, n.2, p. 34-56, 2019. DOI: https://doi.org/10.37444/issn-25945343.v3i2.142

Recebido: 04/03/2019.

Aceito: 20/6/2019. 